\title{
Knowledge, Practices, and barriers to accurate blood pressure measurement procedure among Nurses Caring Cancer Patients under Anthracycline Chemotherapy in Tanzania: Implication of the Neumans theory and the Theory of planned behavior.
}

\section{Bankanie Vicent}

Central South University Xiangya School of Medicine

Athanas Lilngulu

The University of Dodoma College of Health Sciences

Li Yinglan ( $\square$ lyinglan@gmail.com )

Central South University Xiangya School of Nursing

Research article

Keywords: Hypertension, Accurate blood pressure measurement, Blood pressure measurement, Blood pressure, Theory of planned behaviour

Posted Date: January 28th, 2020

DOI: https://doi.org/10.21203/rs.2.22073/v1

License: (c) (i) This work is licensed under a Creative Commons Attribution 4.0 International License. Read Full License 


\section{Abstract}

Patients under anthracycline chemotherapy are at risk of cardiovascular disorders, including hypertension. Error in blood pressure measurement exceeding $5 \mathrm{mmHg}$ may have detrimental outcomes to the patient quality of care. Studies involving nurses reveal discrepancies in knowledge and practices, which raise questions on the reliability of their BP recordings. It is not clear whether nurses taking care of these patients have sufficient knowledge and compliance regarding accurate blood pressure measurement.

This study aimed at assessing knowledge, practice and associated factors regarding accurate blood pressure measurement procedures among nurses caring for cancer patients under anthracycline chemotherapy in Tanzania, guided by the Theory of Planned Behavior and Neuman's Prevention and Intervention Theory.

Methods A cross-sectional study, with a quantitative approach was conducted among 181 nurses who were conveniently sampled from various hospitals in Tanzania. A structured questionnaire was used for data collection and analysis done by using statistical package for social sciences (SPSS) version 21. Descriptive statistics, Chi-square and Binary logistic regression analysis were applied.

Results Based on the given 18 items to assess nurses' knowledge of accurate blood pressure measurement, the mean knowledge score was $8.6(\mathrm{SD}=3.6)$, implying poor knowledge. Those with a bachelor of Nursing and above were more knowledgeable than those with a diploma and below $(A O R=2.5,95 \% \mathrm{Cl}=1.281-4.914, \mathrm{p}=0.007)$. Out of the maximum practice score of 40 , the nurses had Mean=16 (SD=2.33) implying poor practice. Three mostly reported barriers were: Feeling unempowered, Nurses' workload, and unconducive working environment. The results conform to the theory of planned behavior and Neuman's Prevention and Intervention Theory.

Conclusion Nurses caring for patients in anthracycline chemotherapy in Tanzania have poor knowledge and poor practice regarding accurate blood pressure measurement.

Institutional programs to educate nurses about accurate blood pressure measurement may have an impact on attitude and intention to practice accurate blood pressure measurement.

Considering the barriers to accurate blood pressure measurement, and the impact of unstable blood pressure and hypertension on morbidity and mortality in cancer patients at risk of cardiovascular complications, efforts are needed to overcome the barriers and maximize the quality of Blood Pressure measurement by the nurses.

\section{Introduction}

Blood pressure (BP) measurement is a basic clinical nursing skill frequently performed by nurses in their daily nursing care. When performed accurately, BP measurement data helps in guiding the diagnosis of 
hypertension[1],vasoactive drug titration[2],detection of patient clinical deterioration[3],and goal-directed treatment [4].

It is estimated that the rise by the only $5 \mathrm{mmhg}$ in systolic blood pressure(SBP) may result in about a $25 \%$ increase in the risk of fatal cardiovascular complications such as stroke and myocardial infarction[5]. This risk may further increase in patients who are taking drugs that are associated with cardiovascular complications, such as anthracyclines. In this regard, any underestimation made during blood pressure measurement can be fatal to patients. Conversely, an overestimation of the blood pressure would expose the patient to adverse drug effects and unnecessary costs, in addition to the psychological effects of misdiagnosis[6]. Therefore, the measurement of blood pressure should be such accurate that the error does not exceed $5 \mathrm{mmhg}$.

Anthracyclines are broad-spectrum anticancer used in the management of various tumors but are associated with several cardiovascular complications [7-13]. Therefore, in patients treated with this group of drugs, monitoring of cardiovascular indices including blood pressure, are important in determining patient deterioration to intervene accordingly. In this regard, in Tanzania, blood pressure measurement by nurses is usually done every time the patient comes to the clinic, and just before and after IV anthracycline infusion, and anytime the patient goes to the hospital for treatment or follow up, to discover any change that may be ascribed to the chemotherapy.

During the routine nursing care, it is assumed that nurses have adequate knowledge and skills in measuring blood pressure accurately and their recordings are considered correct and reliable. In many hospitals, this is among the procedures in nursing practices that seem simple and do not necessarily require a guideline. Therefore, it is unlikely to meet any guide on blood pressure measurement in clinical practices. However, several errors in blood pressure measurements have been reported among nurses and other clinicians, which raise questions on the accuracy and reliability of the daily BP recordings of the blood pressure[14]. This incorrect blood pressure measurement and recording may detrimentally affect the quality of healthcare received by patients. Sources of errors that should be avoided before or during blood pressure measurement can be patient-related, device-related, or procedure-related and have been well summarized in a recent review[15].

In cancer clinics, blood pressure is usually done in a sitting position, unless the patient is in serious condition or bedridden, where the supine position is used. However, in the supine position, BP tends to vary slightly from the actual value. The SBP in the supine position may be reduced by up to $11 \mathrm{mmHg}$ or increased by up to $9.5 \mathrm{mmHg}$ from the actual values, and the DBP reduced by 13.4 or increased by up to $6.4 \mathrm{mmHg}[15]$.

Ideally, an initial step in measuring BP is to prepare the equipment and settings that are quiet, free of interruptions and is at room temperature of around 20-25 centigrade. Before the procedure, the patient is allowed to empty the bladder if in need. After sitting comfortably with the back supported, and legs lie flat on the floor[16], the nurse further assesses for recent eating, smoking, and caffeine use or exercise. If any of these is "yes", then the measurement should be delayed for about 30 minutes. Otherwise, the patient 
rests for about 3-5 minutes before the procedure. During the procedure, the patient's bared arm should be supported on a hard surface such as a table, to limit the effect of isometric exercise that can increase BP measurements. It is suggested that the midpoint of the patient's upper arm be at the level of the patient's right atrium.

The nurse makes sure that, for the mercury sphygmomanometers, the mercury flows freely and no dirty or bubbles that can impair its floor. The mercury meniscus should read zero at full deflation. Any leakage in the exhaust valves should be checked and the size of the cuff correctly selected according to the size of the patient arm. In cuff selection, the nurse may use a tape measure or the manufacturer's markings on the cuff in order to determine the correct size of the cuff. The BP cuff bladder length and width should be $75 \%-100 \%$ and $37 \%-50 \%$ of the patient's measured arm circumference respectively, or the nurse may simply use the $80 / 40$ rule.

The nurse locates the brachial artery by palpation and places the centered bladder of the cuff over the brachial artery. The cuff should be wrapped smoothly and snugly around the patient's arm, with the lower edge one inch or 2.5 centimeters above the bend in the elbow. To ensure the correct reading, the aneroid dial should be placed at the eye level and making sure that it is easily visible to the nurse. The cuff tubing should also be checked for obstruction. For auscultatory determinations, the nurse should use a palpated estimate of radial pulse obliteration pressure to estimate SBP[16].

During the estimation of the radial pulse obliteration, it is suggested that the first and second fingers firmly placed over the patient's radial pulse and the cuff inflated to approximately $70 \mathrm{mmhg}$ and at $10 \mathrm{~mm}$ $\mathrm{Hg}$ increments until the patient's pulse disappears, and then quickly to a level $20-30 \mathrm{~mm} \mathrm{Hg}$ over palpate estimate. The cuff is then deflated at a steady rate of $2-3 \mathrm{~mm} \mathrm{Hg} / \mathrm{second}$. Systolic blood pressure is obtained at phase 1 and diastolic at phase 5 or 4 of the Korotkoff sound. In recording the BP readings, the cuff size, arm used, patient position and time of the day are recorded and the nurse waits for one to two minutes before rechecking. This is because, for the first time, blood pressure should be taken on both arms and the arm with the highest blood pressure reading is usually used for subsequent readings. The nurse explains the results to the patient, both in verbal and written form, and any need to follow up. Throughout the procedure, the nurse should be aware and able to control for the factors that may affect the accuracy of the blood pressure readings. This is because, although the magnitude of the effect of each factor ranges from small to large in both the positive and negative directions, the cumulative effects of more than one factor may result in fatal inaccuracy in blood pressure readings.

In fulfilling the above procedure, nurses should be equipped with the necessary knowledge. The key assumption is that, if the nurses are not satisfactorily knowledgeable about the factors affecting accurate blood pressure measurement, they will be unlikely to report accurate readings.

However, studies regarding knowledge and practices regarding accurate blood pressure measurement among this population of nurses are limited. To our knowledge, this is the first study around this topic, involving nurses caring for cancer patients under anthracycline chemotherapy alone, using the two combined theories. 


\section{Conceptual and Theoretical framework}

The conceptual framework for this study is a synthesis of two theories, Neuman's Prevention and Intervention Theory[17] and Ajzen's Theory of Planned Behavior (TPB) by Ajzen[18].

According to Neuman theory, nurses assist clients in retaining, attaining, and sustaining optimal stability by implementing the preventive measures. These measures include primary, secondary, and tertiary prevention to reduce risk factors that may allow stressors to attack the clients' defense system.

Primary preventions occur before the system reacts to the stressors and includes health promotion and maintenance of wellness and strengthen the flexible line of defense through preventing stress and reducing risk factors.

Secondary prevention includes health screening and strengthening the internal lines of resistance. The main intention is to identify the stressor early to regain optimal system stability and to conserve energy in doing so.

Tertiary prevention includes treatment of diseases. According to Neuman, nurses' intention is to enable clients to acquire optimal health through prevention. Neuman's theory therefore, supports that one of the important nursing intentions is to assist the patient at risk in correctly identifying his or her blood pressure status in order to implement the preventive measures. This is done by accurately measuring blood pressure of the patient, report the findings to the patient,record the findings, and discuss with the patient the prevention strategies. These prevention strategies may be primary that protect the normal line and strengthen the flexible line of defense against high blood pressure and adapting to healthy life styles and health promotion activities, secondary preventive measures that will strengthen the internal lines of resistance against hypertension, or tertiary, if the patient is hypertensive, by addressing treatment measures in order to maintain or restore the clients' blood pressure stability throughout anthracycline treatment.

The practice of the accurate blood pressure measurement as a behavior, can be explained using the theory of planned behavior. Based on the TPB, three determinants influence behavior intention which is a proxy measure of the behavior (in our case, accurate measurement of blood pressure): 1. attitudes toward the behavior which refer to the individual's positive and negative feeling of the behavior and its outcomes 2. subjective norms, which are the individual's perception of the social environment surrounding the behavior; and 3. perceived control over the performance of the behavior.

Therefore, the attitudes, normative belief and perceived behavioral control regarding accurate blood pressure measurement predicts the nurses' intention, the practice of accurate blood pressure measurement. A nurse will have the intention to practice accurate BP measurement when he/she evaluate it positively ( attitude), believe that the important others in the clinical setting think he/she should perform it (normative belief), and perceive it to be within his/her own control(perceived Behavioral Control)[18]. 
Theoretically, knowledge affects attitude[17], and therefore intention to performance the behavior. Therefore, if nurses have adequate knowledge on accurate blood pressure measurement, then they are likely to practice the accurate blood pressure measurement behavior. Consistent to this, nurses with higher nursing education may have greater knowledge and practice scores than those with lower level of nursing education.

The barriers to practice of accurate blood pressure measurement are those factors that will negatively affect the attitude, and/or Normative beliefs and/or Perceived behavior.

In this study the perceived barriers to accurate blood pressure measurements include: Inadequate resources, Patient behaviors, Lack of guidelines, Unconducive working environment, Feeling unempowered, and Nursing workload.the combined model for the two theories in explaining the practice of accurate blood pressure measurement has been summarized in figure 1 .

Fig 1: The combined model of the theory of planned behavior and the neuman system models in explaining role of knowledge, practice, barriers and outcomes of accurate blood pressure measurement among cancer patients treated with anthracyclines.

\section{Methods}

Aim of this study

This study aimed to assess knowledge, practice and associated factors regarding accurate blood pressure measurement procedures among nurses caring for cancer patients under anthracycline chemotherapy in Tanzania, guided by the Theory of Planned Behavior and the Neuman's Prevention and Intervention Theory.

\section{Design and setting}

A cross-sectional study, with a quantitative approach, was conducted among cancer Nurses caring for patients under anthracycline chemotherapy in Tanzania, from October, 2018 to June 2019.

All nurses who are currently caring or have ever cared for cancer patients under anthracycline chemotherapy were included in the study. The sample size included nurses from Ocean Road Cancer Institute (ORCI), Muhimbili National Hospital in Dar es Salaam, as well as from other major hospitals in Tanzania who were conveniently obtained in the Dodoma region, where they are attending their upgrading courses in different Nursing colleges.

Sample size and sampling technique

Sample size calculation

The Sample size was calculated using the formula below: 
$\mathrm{n}=\underline{\underline{Z}} \underline{\underline{2}} \underline{S D} \underline{\underline{2}}$

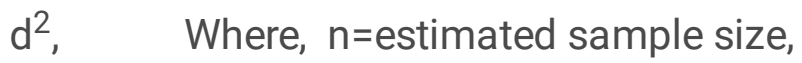

$Z=$ standard normal variate, which is 1.96 (at $P<0.05)$, and

$S D=$ standard deviation calculated from the pilot study

The absolute error (precision), estimated to be 0.6

Therefore, $n=1.96 \times 1.96 \times 4 \times 4,=170.74$

$0.6 \times 0.6$

Adjusting for $10 \%$ none response rate,

Sample size $=$ calculated sample size $(n) \times 1 /$ Response rate

$=189.7$, equivalent to $=190$ participants .

Sampling technique

Convenient sampling was done. All nurses who have ever cared cancer patients under anthracycline chemotherapy and willing to participate in the study, were include until the sample size was reached. The sampling procedure for the study has been summarized in Figure 2 .

Fig 2: Sampling procedure for the participant nurses in Tanzania

Data collection and data collection methods

A questionnaire for the assessment of knowledge was developed based on the American Heart Association guidelines, and other recently published literature[15, 16, 19, 20]. It had two major parts: Demographic item, the questions for assessment of knowledge. There were 18 knowledge questions in which participants were required to answer TRUE if they agree with the statement as true, FALSE if the statement is false or I DON'T KNOW if the participant does not know or is not sure about the truth of the statement. The I DON'T KNOW choice was placed to minimize guessing. Each right answer constituted 1 score, and the sum of knowledge scores were finally classified as follows: 0-9 = poor, 10-14 =moderate and 15-18 = adequate knowledge.

The practice was assessed by a checklist with the items of a standardized measurement method which was also constructed based on the review of the literature[1, 6, 24, 25, 14-16, 19-23]. The participant nurses were required to report whether they always adhere to each of the 20 items during blood pressure measurement. The scores ranged from 2 for always complying, 1 for sometimes and 0 for never 
complying. Results were tabulated and the score categorized as follows: 0-20 was poor practice, and 2130 was moderate and 31-40 was good practice. In addition, the barriers to the practice of accurate blood pressure measurements were presented on the checklist and the participant nurses were required to answer YES if they agree with it as a barrier to the practice of accurate blood pressure measurement, and NO if they don't agree.

\section{Validity and reliability}

A panel of 2 Clinical Nurse specialists assessed the content validity of the questionnaire and their suggestions led to the improvement of the questionnaire. A pilot study was conducted among 20 nurses from Dodoma Regional Hospital who were not included in the study. From the results of the pilot study, the standard deviation was estimated which led to the calculation of the sample size and improvement of the clarity of the questions. The knowledge instrument had acceptable internal consistency reliability with a Cronbach a of 0.71 .

Statistical analysis

Raw data were uploaded and analyzed using Statistical Package for the Social Sciences (SPSS) version 21. Descriptive statistics (mean, median, percentages, and percentiles) was applied to evaluate the participants' overall knowledge, practice scores and the perceived barriers to accurate blood pressure measurement. Inferential statistics such as chi-square and logistic regression analysis were applied to determine the factors associated with knowledge and practice related to accurate blood pressure measurements. All results assumed a two-tailed distribution with an alpha (a) level of $5 \%$.

\section{Results}

\section{Socio-demographic characteristics}

A total of 181 nurses equivalent to $95 \%$ of the estimated sample size were involved in the study. The demographic information of the participants is summarized in table 1. Nurses aged between 30-39 years constituted the largest proportion (50.8\%). Most had a nursing education of diploma level in nursing (51.9\%). Among the participants, 79\% were females. All participant nurses reported being confident in taking blood pressure correctly. None of the participants have ever attended any recent course in blood pressure measurements.

\section{Table 1: Demographic characteristics of participant nurses}




\begin{tabular}{|l|l|l|}
\hline Variable & Frequency & Percent \\
\hline Age (n=115) & & \\
\hline $20-29$ & 46 & 25.4 \\
\hline $30-39$ & 92 & 50.8 \\
\hline $40-49$ & 42 & 23.2 \\
\hline $50-59$ & 1 & 0.6 \\
\hline Level of nursing education (N=115) & & \\
\hline Certificate & 4 & 2.2 \\
\hline Diploma & 94 & 51.9 \\
\hline Degree & 80 & 44.2 \\
\hline Postgraduate & 3 & 1.7 \\
\hline Experience & & \\
\hline Less than 5 years & 102 & 56.4 \\
\hline Greater than 5ears & 79 & 43.6 \\
\hline Sex (N=116) & & \\
\hline Male & 30 & 16.6 \\
\hline Female & 151 & 83.4 \\
\hline Are you confident in taking blood pressure correctly? & & \\
\hline Yes & 181 & 100 \\
\hline No & - & 0 \\
\hline Had any recent training on blood pressure measurement? & & \\
\hline Yes & 0 & 0 \\
\hline No & 100 & 100 \\
\hline & & \\
\hline
\end{tabular}

\section{Knowledge on accurate blood pressure measurement}

The mean knowledge score was 8.6(SD=3.6) implying an overall poor knowledge. Only

$5.5 \%$ had adequate knowledge, ie above (15/18) scores. The scores range from $0-17$, with a median score of 9. Both the Kolmogorov -Smirnov, and Shapiro-Wilk test were significant ( $p=0.037$ vs 0.023$)$, implying that the scores were not normally distributed $(p=0.000)$. The box plot revealed no outliers. The 75th percentile was 11 .

The three items scored most were: "bladder distension" as among the variables that influence BP (65.7\%), whether the patient should be at rest for 5 minutes before BP measurement (60.8\%) whether the "arm should be level with the heart" (58\%). 
The item scored least was whether the "stethoscope diaphragm should not be put under the cuff" (32\%), whether "the first measurement of BP should be in both arms" (35.4\%), and whether "crossing legs can raise BP" (36.5\%), (Table 2).

Table 2: Items for assessment of knowledge and the proportion of participant nurses who scored the wrong and right answers in each of the knowledge items. 


\begin{tabular}{|c|c|c|}
\hline & Item & $\begin{array}{l}\text { Correct } \\
\text { answers } \\
\mathrm{f}(\%)\end{array}$ \\
\hline & Most Precise sphygmomanometer use mercury & $90(49.7)$ \\
\hline & $\mathrm{BP}$ readings should be to the nearest even number $(2 \mathrm{mmhg})$ & $104(57.5)$ \\
\hline & Variables that influence BP & \\
\hline & Cuf defletion rate & $88(48.6)$ \\
\hline & Having eaten recently & $99(54.7)$ \\
\hline & Having smoked recently & $95(52.5)$ \\
\hline & Recent physical activities & $98(54.1)$ \\
\hline & Bladder distension & $119(65.7)$ \\
\hline & Cuff bladder length should be at least $75 \%$ of arm circumference & $87(48.1)$ \\
\hline & The arm should be level with the heart & $105(58)$ \\
\hline . & $\begin{array}{l}\text { Diastolic pressure correspond to } \mathrm{BP} \text { at the point when the } \\
\text { auscultatory gap occurs }\end{array}$ & $66(36.5)$ \\
\hline . & The stethoscope diaphragm should not be put under the cuff & $58(32)$ \\
\hline 12. & $\begin{array}{l}\text { The cuff should be inflated to at least } 20 \mathrm{mmhg} \text { above the } \\
\text { disappearance of brachial pulse. }\end{array}$ & $75(41.4)$ \\
\hline . & Room temperature should be $20-25 \mathrm{C}$ & $87(48.1)$ \\
\hline$=$ & First measurement of BP should be in both arms & $64(35.4)$ \\
\hline . & Crossing legs can raise $\mathrm{BP}$ & $66(36.5)$ \\
\hline b. & The patient should be at rest for 5 minutes before BP measurement & $110(60.8)$ \\
\hline . & BP should be measured at least twice in each session & $76(42)$ \\
\hline . & $\begin{array}{l}\text { Diagnosis of Hypertension requires having elevated BP on at least } \\
2 \text { measurements on } 2 \text { or more visits }\end{array}$ & $72(39.8)$ \\
\hline
\end{tabular}


Factors associated with knowledge regarding accurate blood pressure measurement among nurses caring for Cancer patients under Anthracycline treatment.

Because of the lower number of nurses with adequate knowledge, the knowledge scores were re-classified as poor knowledge (for scores <9) and moderate to adequate scores (>9). A chi-square test was applied to discover whether there was any relationship between knowledge and the participant demographic characteristics. Only the level of nursing education was significantly associated with knowledge scores (Table 3).

Table 3: Factors associated with knowledge accurate blood pressure measurement among Nurses caring cancer patients under Anthracycline chemotherapy in Tanzania

\begin{tabular}{|c|c|c|c|c|}
\hline Variable & $\begin{array}{c}\text { Poor } \\
\text { knowledge } \\
(<9)\end{array}$ & $\begin{array}{l}\text { Moderate to adequate } \\
\text { knowledge } \\
(10-18)\end{array}$ & $\begin{array}{l}\text { Chi square } \\
\text { value }\end{array}$ & p-value \\
\hline \multicolumn{3}{|l|}{ Age $(n=115)$} & \multirow{5}{*}{2.855} & \multirow{5}{*}{0.415} \\
\hline $20-29$ & 23 & 23 & & \\
\hline $30-39$ & 56 & 36 & & \\
\hline $40-49$ & 27 & 15 & & \\
\hline $50-59$ & 1 & 0 & & \\
\hline \multicolumn{5}{|c|}{ Level of nursing education ( $\mathrm{n}=115)$} \\
\hline $\begin{array}{l}\text { Certificate or } \\
\text { Diploma }\end{array}$ & 68 & 30 & \multirow[t]{2}{*}{9.329} & \multirow[t]{2}{*}{$0.002^{* *}$} \\
\hline above ${ }^{\text {Degree and }}$ & 39 & 44 & & \\
\hline \multicolumn{5}{|l|}{ Experience } \\
\hline Less than 5 years & 44 & 31 & \multirow[b]{2}{*}{0.031} & \multirow[b]{2}{*}{0.86} \\
\hline $\begin{array}{l}\text { Greater than } 5 \\
\text { years }\end{array}$ & 51 & 38 & & \\
\hline \multicolumn{5}{|l|}{$\operatorname{Sex}(N=116)$} \\
\hline Male & 20 & 10 & \multirow[b]{2}{*}{0.848} & \multirow[b]{2}{*}{0.357} \\
\hline Female & 87 & 64 & & \\
\hline
\end{tabular}

After adjusting for other factors, those having degree or above were about three times more knowledgeable than those with diploma or below (Table 4). 
Table 4: Adjusted odd ratio (AOR) for the effect of Nursing educational level on knowledge regarding accurate blood pressure measurement among Nurses caring Anthracycline chemotherapy in Tanzania.

\begin{tabular}{llll}
\hline Variable & AOR & 95\%CI & P value \\
\hline Education & & & \\
Certificate or diploma & 1 & & \\
Degree and above & $\mathbf{2 . 5 3 3}$ & $\mathbf{1 . 3 7 7 - 4 . 6 6 1}$ & $\mathbf{0 . 0 0 3}$ \\
\hline
\end{tabular}

Practice related to accurate blood pressure measurement

A total of $164(91 \%)$ were filled in the checklist for the assessment of practice.

The mean practice score was $16(S D=2.33)$ implying poor practice. The three items reported always practiced by the majority of participants were: positioning the patients with their feet flat on the floor (81.7\%), correct choice of the arm (48.8\%) and letting the patient rest for approximately 5 minutes before the procedure (44.5\%).

The three items reported always practiced by minority include: Checking for calibrated instruments ( $0 \%)$, Assessment for recent Smoking (0\%), Documentation of which arm was used (0\%), Documentation of the time of the day $(0 \%)$ and Assessing the need to empty bladder (1.8\%). Therefore, the probability that a nurse will comply with all the necessary items for accurate blood pressure measurement is 0 .

Table 4: The observational checklist for assessment of practice and the proportion of participant nurses who performed correctly in each of the items. 


\begin{tabular}{|c|c|c|c|c|}
\hline No & Item & $\begin{array}{l}\text { Always } \\
\text { (2) }\end{array}$ & $\begin{array}{l}\text { Sometime } \\
\text { (1) }\end{array}$ & $\begin{array}{l}\text { Never } \\
(0)\end{array}$ \\
\hline & Checking for calibrated instruments & $0(0)$ & $59(36)$ & 105(64) \\
\hline & Let patient rest for approximately 5 minutes & 73(44.5) & 56(34.1) & $35(21.3)$ \\
\hline & Assessing the need to empty bladder & $3(1.8)$ & $66(40.2)$ & 95(57.9) \\
\hline & Assessing for & & & \\
\hline & Acute meal, & $6(3.7)$ & 40(24.4) & 118(72) \\
\hline & Acute alcohol ingestion, & $27(16.5)$ & 74(45.1) & 63(38.4) \\
\hline & Acute caffeine use & $8(4.9)$ & $28(17.1)$ & $128(78)$ \\
\hline & Recent Smoking & $0(0)$ & $51(31.1)$ & $113(68.9)$ \\
\hline & Position patient with & & & \\
\hline & Their feet on floor & 134(81.7) & $30(18.3)$ & $0(0)$ \\
\hline & Legs uncrossed & 79(48.2) & $85(51.8)$ & 0 \\
\hline . & Their back supported. & $33(20.1)$ & 129(78.7) & $2(1.2)$ \\
\hline$\cdot$ & $\begin{array}{l}\text { Expose the patient's arm at least } 2-2.5 \mathrm{~cm} \text { above } \\
\text { the elbow }\end{array}$ & 14(8.5) & $150(91.5)$ & $0(0)$ \\
\hline . & Correct choice of the arm & $80(48.8)$ & 82(50) & $2(1.2)$ \\
\hline 3. & Assess for correct size of the cuff & 13(7.9) & 41(25) & $110(67.1)$ \\
\hline$=$. & Arm is supported, & 71(43) & $70(42)$ & $23(14)$ \\
\hline . & $\begin{array}{l}\text { Arm at patient's heart level and palm of hand } \\
\text { turned up }\end{array}$ & $36(22)$ & 71(43.3) & 57(34.8) \\
\hline . & $\begin{array}{l}\text { Both you and the client remain quiet during } \\
\text { measurement }\end{array}$ & $40(24.4)$ & 96(58.5) & 28(17.1) \\
\hline . & First measurement of BP in both arms & $5(3)$ & $52(31.7)$ & 107(61.2) \\
\hline s. & Reliance on 2 measurements rather than one & $2(1.2)$ & $39(24.2)$ & 123(74.5) \\
\hline . & Documentation of which arm was used & $0(0)$ & $16(9.8)$ & 148(90.2) \\
\hline . & Documentation of the time of the day & $0(0.0)$ & $1(0.6)$ & 163(99.4) \\
\hline
\end{tabular}

Only 5 (3\%) had moderate practices score regarding accurate BP measurements. There was no association between practice and knowledge scores $(\mathrm{p}=0.6)$, experience $(\mathrm{FET}=0.6)$, or education level (FET=0.397).

\section{Barriers to accurate blood pressure measurement}

Participant nurses were asked about the barriers to accurate blood pressure measurement and the responses have been summarized in table 5 below. 


\section{Table 5: Barriers to accurate blood pressure measurement among nurses caring cancer patient under anthracyclines chemotherapy}

\begin{tabular}{|l|l|l|l|}
\hline & Barrier & $\begin{array}{l}\text { Yes } \\
\mathrm{n}(\%)\end{array}$ & $\begin{array}{l}\text { No } \\
\mathrm{n}(\%)\end{array}$ \\
\hline 1. & Feeling unempowered & $157(95.7)$ & $7(4.3)$ \\
\hline 2. & Nursing workload & $156(95.1)$ & $8(4.9)$ \\
\hline & Unconducive working environment & $152(92.7)$ & $12(7.3)$ \\
\hline & Lack of guidelines & $151(92.1)$ & $13(7.9)$ \\
\hline & Patient behaviors & $137(83.5)$ & $27(16.5)$ \\
\hline & Inadequate resources & $137(83.5)$ & $27(16.5)$ \\
\hline
\end{tabular}

\section{Discussion}

This study aimed to determine the knowledge, practices and associated factors regarding accurate blood pressure measurement procedures in Nurses caring for cancer patients under anthracycline chemotherapy in Tanzania, and relate the results with the theory of planned behavior and the Neuman's Prevention and Intervention Theory. The study has identified areas of limited knowledge and practices in the BP measurement procedure.

In this study, all (100\%) nurses reported to be confident in taking blood pressure and none of them reported to have ever had any training regarding accurate blood pressure measurements (Table1). The overall mean knowledge score was 8.6 (SD=3.6), which implies a poor knowledge level. This was even though majority of the participant nurses had graduated in recent years (the 75th percentile of the working experience was 9 years), and some are upgrading their diploma into degree. Contrary to these results, they would be expected to have a recent knowledge from college, and higher knowledge scores regarding accurate blood pressure measurement. These findings may have several interpretations: 1.What the majority of nurses believe they know about accurate BP measurement does not exactly constitute the correct measurement of blood pressure. 2. It might be that, during their nursing training, little emphasis was provided on accuracy of the blood pressure measurement procedure. 3. Nurses may have considered the BP measurement procedure as a 'simple' procedure which does not require detailed attention. This is reflected in nursing colleges in Tanzania, where in practice, nursing students tend to concentrate more in understanding the procedures that they find more complex than those they term as 'simple' ones. As the result, they fail to perform accurately on those 'simple' procedures. As a result, similar attitude may be affecting their accurate practices in their daily nursing care. Poor knowledge regarding blood pressure measurements has also been reported among general nurses in Scotland[14], and in Australia[19].

Nurses with degree level of nursing education and above are about three times more knowledgeable than those with diploma and below (Table 4).These findings are consistent with the study among general 
nurses in Egypt[26]. The differences in the level of knowledge between nurses with higher and lower levels of education may be explained in terms of the nature of their training. In nurses with diploma and below, training is more on technical know-how, than technical know why, while at degree level and above, more emphasis is made on both the technical know-how and the technical know-why. Therefore, it is likely that, nurses with higher level of nursing education understand more on the physiological implications of most of the steps to take when measuring blood pressure. The differences in knowledge among nurses of the same level of nursing education may be attributed to lack of standardization in teaching of blood pressure measurement among different nursing teaching facilities and hospitals[27].

The findings of this study reveal no relationship between Nurses' experience, the knowledge, and practice of accurate blood pressure measurement (Table 3). These findings are consistent with the study by Zhang et al[28] in China, where the experienced nurses performed poorer in blood pressure measurement than even nursing students. Nurses with higher experience are usually more involved in management than in basic clinical practices such as measurement of vital signs, including blood pressure, which results in losing their original skills in such procedures. These findings support the need for frequent clinical training and recertification, at least every 6 monthly to update and revise the accurate knowledge and practices among nurses and other clinicians[16, 28].

Accurate blood pressure measurement is usually affected by several factors. Fast cuff deflation rate lowers SBP by 9 to $2.6 \mathrm{mmHg}$ but raises DBP by 2.1 to $6.3 \mathrm{mmHg}$ [15]. Bladder distension can raise both the SBP and DBP up to 30 and $18 \mathrm{mmHg}$ respectively[15]. Recent smoking raises both the SBP and DBP by the range of 13 to $14 \mathrm{mmHg}$ and 18 to $25 \mathrm{mmHg}$ respectively[15]. Likewise, recent physical activities raise SBP by 4.2 to $11.6 \mathrm{mmHg}$ and DBP by 1.8 to $4.3 \mathrm{mmHg}$, and recent meal reduces the Systolic Blood Pressure (SBP) by $6 \mathrm{mmHg}$, and diastolic blood pressure (DBP) by the range between $5 \mathrm{mmHg}$ to $1.9 \mathrm{mmHg}[15]$.Therefore, the American Heart Association guideline[16] and the European Society of Hypertension practices[21] emphasize on controlling for these factors before and during the blood pressure measurement procedure. In this study, however, only about half of the participants were knowledgeable about the variables influencing blood pressures, and a negligible number of nurses did usually assess for these factors during blood pressure measurement. This is a single most important evidence that most of the blood pressure recordings deviates from the actual value of the patient.

In this study, only about $48 \%$ of the participants were aware of the size of the cuff bladder required for accurate measurement of blood pressure. These results are consistent to the studies in Hispania[24], USA[29] and Australia[19] among nursing students, where $32.8 \%, 45 \%$ and $57 \%$ were aware of the estimating cuff size required in blood pressure measurement respectively. Nurse should ensure that the cuff bladder length is at least $75 \%$ of arm circumference, and BP cuff bladder of $37 \%-50 \%$ of the patient's arm circumference (a length-to-width ratio of 2:1)[16]. This is because, using too narrow or too short bladders (under cuffing) leads to overestimation of BP while the use of too wide or too long bladders (over cuffing) may lead to BP underestimation[16]. 
The influence of arm position on BP measurement has been severally reported[1, 15, 16]. Kallioinen et al[15] more recently re-evaluated the effect of arm lower than the heart and documented the significant variation of arm systolic blood pressure by 3.7 to $23 \mathrm{mmHg}$, and diastolic pressure by 2.8 to $12 \mathrm{mmHg}$. However, in this study, only $58 \%$ of the participant nurses were aware that the arm should be at the level of the heart during blood pressure measurement. However,this proportion is higher than the reported proportion the recent study in India[30], where only where only $6 \%$ of doctors and $10 \%$ of nurses were aware of the effect of arm position on blood pressure. The differences in knowledge may be attributed to differences in modalities and policies in the teaching of blood pressure measurement among different nursing teaching facilities and hospitals[27].

While all participant nurses reported to be confident in taking blood pressure, only about $36.5 \%$ were aware that diastolic pressures correspond to BP at the point when the auscultatory gap occurs. This has dual interpretations: First, it may be possible that majority do not exactly understand when the diastolic pressure is recorded during auscultation. Second and more likely, the participant nurses may not be understanding the meaning of the auscultatory gap. All these may lead to under-or-overestimation of the diastolic pressure.

Fewer than a half were not aware whether the following factors may affect the blood pressure readings of a patient: crossing legs, first measurement of BP in both arms, and room temperature at 20-25C, BP measured at least twice in each session, and whether diagnosis of hypertension requires having elevated BP on at least 2 measurements on 2 or more visits. All these increases risk for reporting an inaccurate blood pressure reading[15, 16].

Another important observation is that, only about $40 \%$ were aware that BP should be measured at least twice in each session, and the diagnosis of hypertension requires having elevated BP on at least 2 measurements on 2 or more visits. Multiple blood pressure measurement is usually recommended in order to increase the predictive power of the blood pressure measurements [16]. Therefore, it is possible that majority of nurses erroneously classify the patients as hypertensive while they are not, or as nonhypertensive while they are. Both have detrimental effect to the patient care.

The barrier to accurate blood pressure measurement have been summarized in Table 5 . The three mostly reported barriers to practice of accurate blood pressure measurement were : Feeling unempowered (95.7\%), Unconducive working environment (95.1\%) and Nursing workload (92.7\%).Similar findings have been documented by other studies [31].

\section{Implication of the findings to theory of planned behavior and Neuman's Prevention and Intervention Theory}

In this study, there was association between the nurses level of education and the knowledge regarding accurate blood pressure measurement, which is consistent with the hypothesis of this study. Although there was no association between the knowledge and practice scores, but both the knowledge and practice scores were lower, at the level of poor knowledge and poor practice respectively. This is 
consistent with conceptual model, that knowledge affect attitude toward the behavior and the attitude affects intentions which are the proxy measure of the behavior. Therefore,the poor knowledge may have negatively affected the attitude, which results in poor practice of accurate blood pressure measurement(Fig. 2). The poor practices in accurate blood pressure measurements imply the inefficient role of a nurse in correctly identifying the actual and/potential stressors to the patient and mislead the role of a nurse in prevention and stabilizing the patient systems through interventions to reduce stressors.

Consistent with the conceptual model of this study, barriers to practice of accurate blood pressure measurement negatively affect the attitude and the perceived behavioral control.These in turn, negatively affect the practice the accurate blood pressure measurement, explained by low practice scores in this study.

In summary, nurses caring patients under anthracycline chemotherapy in Tanzania have poor knowledge and practices regarding accurate blood pressure measurement. The poor knowledge, and the barriers to accurate blood pressure measurement, negatively affects the attitude and the perceived behavioral control, which in turn negatively affects the intention and practice of accurate blood pressure measurement. The poor practice implies that the blood pressure recordings commonly done by the nurses, are likely to have false negative and false positive diagnoses of hypertension. In accordance with the Neumans'model therefore, which stipulates the role of the nurse as a person who collaborates with the client (individuals or families) to maintain a utmost level of wellness, and stability of the client systems by performing nursing interventions to reduce stressors, becomes misled and the patients' risks remain unprevented.

\section{Limitations of the study}

This study has some limitations. First, the use of cross-sectional study design does not provide a causaleffect relationship between the variables. Secondly, the convenience sampling method used in this study limits the generalizability of the findings.

\section{Conclusion And Recommendations}

This is the first study to aiming to assess the knowledge, practice and barriers to accurate blood pressure measurement among nurses taking care of cancer patients under anthracycline chemotherapy alone.

The level of knowledge and practice in this population of nurses is poor. The two biggest barriers to accurate blood pressure measurement were nurses feeling of unempoweredness, and the nurses' workload. The fact that nurses with degree of nursing or higher demonstrated higher knowledge than those with low nursing educational level suggests the need to upgrade nursing educational levels by nurses, especially those involved in care of patients who are in unpredictable cardiovascular situations such as cancer patients under anthracycline chemotherapy. 
Considering the poor knowledge, the barriers to accurate blood pressure measurement, and the impact of unstable blood pressure and hypertension on morbidity and mortality in cancer patients at risk of cardiovascular complications due to anthracyclines chemotherapy, efforts are needed to maximize the quality of BP measurement in cancer hospitals and clinics.

\section{Abbreviations}

BP: Blood pressure;

SBP: Systolic Blood Pressure

DBP: Diastolic Blood Pressure

TPB: Theory of Planned Behavior

ORCl: Ocean Road Cancer Institute

FET: Fisher's exact test

\section{Declarations}

\section{Acknowledgements}

The authors would like to acknowledge the Central Scholarship committee in China (CSC) and the the Natural Science Foundation of Hunan Province for their financial support. We also thank the nurses in Tanzania who consented to participate in this study.

\section{Authors' contributions}

All authors participated in writing the research proposal, developing the questionnaire, analysis of data, writing the paper and interpreting the findings. BV and AL trained data collectors, checked for quality of data, and performed data analysis. All the authors reviewed contributed and reviewed the manuscript document. LY was the overall supervisor in all the steps.

\section{Funding}

Funding for this study was sponsored by "The Natural Science Foundation of Hunan Province, China (Grant No.2019JJ40403)"

\section{Availability of data and materials}

All data were available in this manuscript. 


\section{Ethics approval and consent to participate}

The ethical clearance was granted by "UDOM Institution Research Review Committee (IRRC)" with number (UDOM/DRP/134/VOLVI) and permission to collect data was given from ocean Road Cancer Institute, Muhimbili National Hospital and the University of Dodoma, and St.John's University of Tanzania. The participants were guaranteed of the right to withdraw from the study at any time. A consent form was given to those who were willing to participate in the study. Enough time to read the form and ask questions was provided. Each participant signed two consent forms; and was given a copy of the original signed form to keep.

\section{Consent for publication}

The article does not contain any individual's details, video or images; and hence, consent for publication is not applicable.

\section{Competing interests}

The authors have no any competing interests.

\section{References}

1. Pickering TG, Hall JE, Appel LJ, Falkner BE, Graves J, Hill MN, et al. Recommendations for Blood Pressure Measurement in Humans and Experimental Animals. Hypertension. 2005;45:142-61.

2. Hollenberg SM, Ahrens TS, Annane D, Astiz ME, Chalfin DB, Dasta JF, et al. Practice parameters for hemodynamic support of sepsis in adult patients: 2004 Update. Critical Care Medicine. 2004.

3. Jones D, Drennan K, Hart GK, Bellomo R, Steven AR. Rapid Response Team composition, resourcing and calling criteria in Australia. Resuscitation. 2012;83:563-7.

4. Holley A, Lukin W, Paratz J, Hawkins T, Boots R, Lipman J. Review article: Part two: Goal-directed resuscitation - Which goals? Perfusion targets. Emerg Med Australas. 2012;24:127-35.

5. Lewington S, Clarke R, Qizilbash N, Peto R, Collins R. Age-specific relevance of usual blood pressure to vascular mortality: a meta-analysis of individual data for one million adults in 61 prospective studies. Lancet. 2002;360:1903-13.

6. Jones DW, Appel LJ, Sheps SG, Roccella EJ, Lenfant C. Measuring Blood Pressure Accurately. JAMA. 2003;289:1027.

7. Raschi E, Vasina V, Grazia M, Boriani G, Martoni A, Ponti F De. Pharmacology \& Therapeutics Anticancer drugs and cardiotoxicity: Insights and perspectives in the era of targeted therapy. Pharmacol Ther. 2010;125:196-218. doi:10.1016/j.pharmthera.2009.10.002.

8. Vandecruys E, Mondelaers V, De Wolf D, Benoit Y, Suys B. Late cardiotoxicity after low dose of anthracycline therapy for acute lymphoblastic leukemia in childhood. J Cancer Surviv. 2012;6:95- 
101. doi:10.1007/s11764-011-0186-6.

9. Horenstein MS, Vander Heide RS, L’Ecuyer TJ. Molecular basis of anthracycline-induced cardiotoxicity and its prevention. Mol Genet Metab. 2000;71:436-44.

10. McGowan J V, Chung R, Maulik A, Piotrowska I, Walker JM, Yellon DM. Anthracycline Chemotherapy and Cardiotoxicity. Cardiovasc Drugs Ther. 2017;31:63-75. doi:10.1007/s10557-016-6711-0.

11. Tokarska-Schlattner M, Zaugg M, Zuppinger C, Wallimann T, Schlattner U. New insights into doxorubicin-induced cardiotoxicity: The critical role of cellular energetics. J Mol Cell Cardiol. 2006;41:389-405.

12. Volkova M, Russell R, Russell lii R. Anthracycline cardiotoxicity: Prevalence, pathogenesis and treatment. Curr Cardiol Rev. 2011;7:214-20. doi:10.2174/157340311799960645.

13. Mele D, Nardozza M, Spallarossa P, Frassoldati A, Tocchetti CG, Cadeddu C, et al. Current views on anthracycline cardiotoxicity. Heart Fail Rev. 2016;21:621-34.

14. Gillespie A, Curzio J. Blood pressure measurement: assessing staff knowledge. Nurs Stand. 1998;12:35-7.

15. Kallioinen N, Hill A, Horswill MS, Ward HE, Watson MO. Sources of inaccuracy in the measurement of adult patients' resting blood pressure in clinical settings: A systematic review. J Hypertens. 2017;35:421-41.

16. Muntner P, Shimbo D, Carey RM, Charleston JB, Gaillard T, Misra S, et al. Measurement of Blood Pressure in Humans: A Scientific Statement From the American Heart Association. 2019.

17. Ume-Nwagbo PN, DeWan SA, Lowry LW. Using the Neuman systems model for best practices. Nurs Sci Q. 2006;19:31-5.

18. Netemeye R, Ryan Van M, Adjen I. "The theory of planned behavior," Organizational Behavior and Human Decision Processes. 1991.

19. Armstrong RS. Nurses' knowledge of error in blood pressure measurement technique. Int J Nurs Pract. 2002;8:118-26.

20. Saugel B, Dueck R, Wagner JY. Measurement of blood pressure. Best Pract Res Clin Anaesthesiol. 2014;28:309-22. doi:10.1016/j.bpa.2014.08.001.

21. Parati G, Stergiou GS, Asmar R, Bilo G, Leeuw P De, Imai Y, et al. European Society of Hypertension Practice Guidelines for home blood pressure monitoring. J Hum Hypertens. 2010;24 June:779-85.

22. Drevenhorn E, Håkansson A, Petersson K. Blood pressure measurement - an observational study of 21 public health nurses. Clin Nurs Res. 2001;10:189-94.

23. Adiyaman A, Tosun N, Elving LD, Deinum J, Lenders JWM, Thien T. The effect of crossing legs on blood pressure. Blood Press Monit. 2007;12:189-93.

24. González-lópez JJ, Ramírez JG, García T, Esteban SA, Rodríguez-artalejo F. Knowledge of Correct Blood Pressure Measurement Procedures Among Medical and Nursing Students. Rev Esp Cadiol. 2009;62:5-8. 
25. Weber F, Anlauf M, Hirche H, Roggenbuck U, Philipp T. Differences in blood pressure values by simultaneous auscultation of Korotkoff sounds inside the cuff and in the antecubital fossa. J Hum Hypertens. 1999;13:695-700.

26. Mohammed Labib Weheida S, Mahmoud Hafez Mohammed E, Fathy Amr Mohammed Aly E. Blood Pressure Measurements: Factors Affecting Readings Accuracy. liosrjournalOrg. 2017;6:71-86. doi:10.9790/1959-0605077186.

27. Duggan PM, Miller J. Blood Pressure Measurement in Pregnancy: A survey of methods used in teaching hospitals in South Australia. Aust New Zeal J Obstet Gynaecol. 1998;38:197-9. doi:10.1111/j.1479-828X.1998.tb03001.x.

28. Zhang $M$, Zhang X, Chen F, Dong B, Chen A, Zheng D. Effects of room environment and nursing experience on clinical blood pressure measurement: An observational study. Blood Press Monit. 2017;22:79-85.

29. Crosley AM, Rose JR La. Knowledge of accurate blood pressure measurement procedures in chiropractic students. J Chiropr Educ. 2013;27:152-7. doi:10.7899/JCE-13-3.

30. Mohan B, Aslam N, Ralhan U, Sharma S, Gupta N, Singh VP, et al. Office blood pressure measurement practices among community health providers (medical and paramedical) in northern district of India. Indian Heart J. 2014;66:401-7. doi:10.1016/j.ihj.2014.07.001.

31. Hwang KO, Aigbe A, Ju H-H, Jackson VC, Sedlock EW. Barriers to Accurate Blood Pressure Measurement in the Medical Office. J Prim Care Community Health. 2018;9:215013271881692. doi:10.1177/2150132718816929.

\section{Figures}




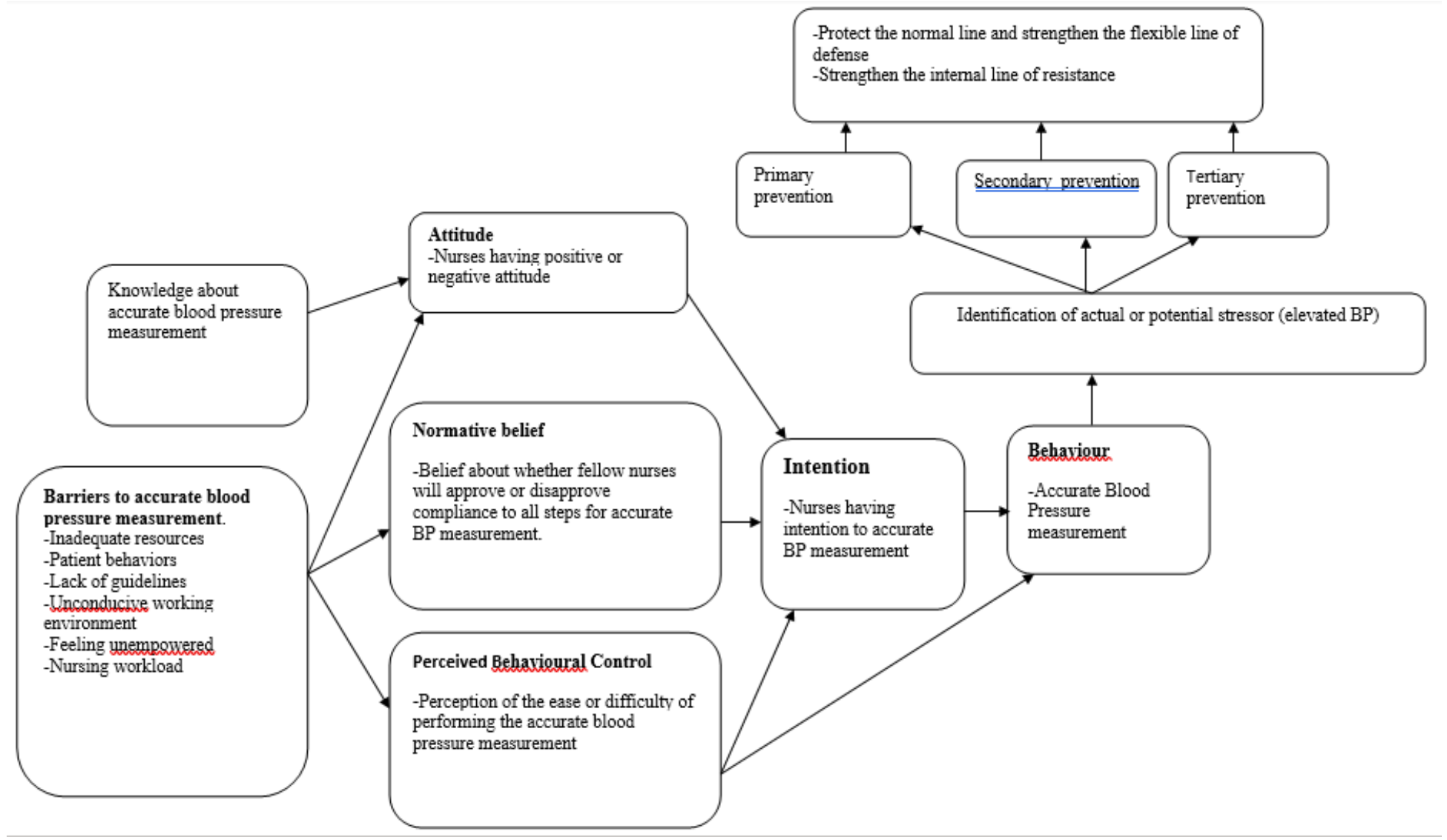

Figure 1

The combined model of the Theory of Planned Behavior and the Neuman System Models in explaining role of knowledge, practice,barriers and outcomes of accurate blood pressure measurement among cancer patients treated with anthracyclines.

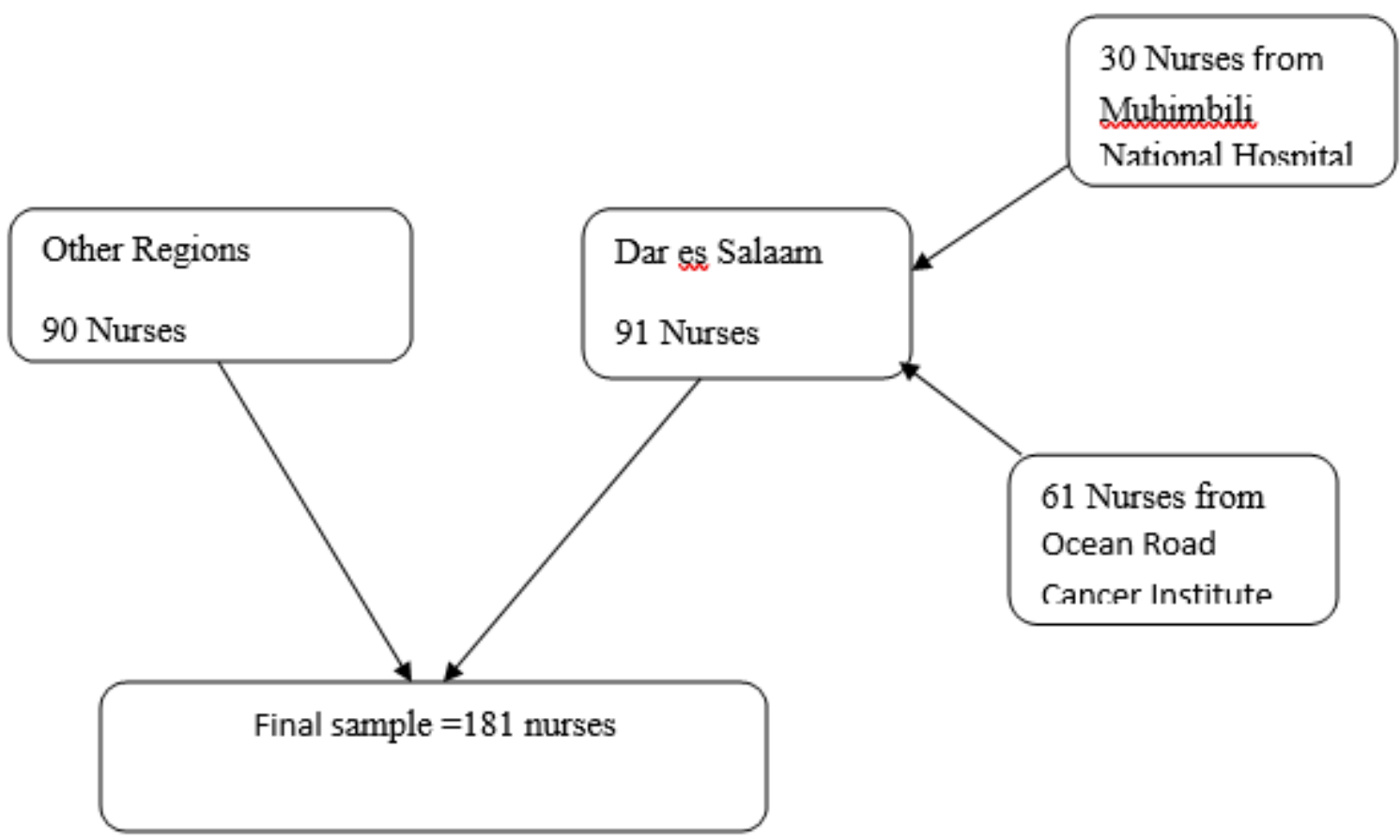


Figure 2

Sampling procedure for the participant nurses in Tanzania 